\title{
Multi Objective Optimization of Long Hollow Simple Drive Shaft Under Multi-axial Non-Proportional Loading
}

\author{
Mohammad Baharvand ${ }^{1}$, Mohammad Pourmohammadi ${ }^{2}$, Mehran Felfeli ${ }^{2}$ \\ ${ }^{1}$ School of Mechanical Engineering, Islamic Azad University of Kermanshah, Kermanshah, Iran \\ ${ }^{2}$ School of Mechanical Engineering, Sharif University of Technology, Tehran, Iran
}

Email address:

m.baharvand64@gmail.com (M. Baharvand),pourmohammadi.86@gmail.com (M. Pourmohammadi), felfeli_1234@yahoo.com (M. Felfeli)

\section{To cite this article:}

Mohammad Baharvand, Mohammad Pourmohammadi, Mehran Felfeli. Multi Objective Optimization of Long Hollow Simple Drive Shaft Under Multi-axial Non-Proportional Loading. Science Discovery. Vol. 3, No. 3, 2015, pp. 17-24. doi: 10.11648/j.sd.20150303.11

\begin{abstract}
This article investigates the effect of bearing Location and length on the shaft life under multi-axial non-proportional loading. The goal of this study is to increase long shaft life by deciding best location for bearing and its length. Loading condition and shaft properties was assumed according to helicopter. The most common case for this study observed in tail rotor of the Helicopter. Tail rotor drive shaft depended on helicopter type consist of 3 to 5 sections due to high length. Normally these sections assumed identical for simple production but it is shown that using non-identical sections is more proper than the other one. Optimization of shaft life and mass with design variable of the bearing locations and length is performed by ANSYS Workbench software and it is observed that these design variables have a major effect in objective functions. In the next step, we optimize maximum bearing pressure by two new advance methods named Genetic algorithm (GA) and Particle swam algorithm (PSO) and compare these algorithm abilities.
\end{abstract}

Keywords: Multi-Axial Non-Proportional Loading, Strain Life, Stress Life, Multi-Objective Optimization, Genetic Algorithm, Particle Swam Algorithm

\section{Introduction}

Many structures are subjected to alternative loading such as Tail rotor drive shaft. It has around 7 to 10 meter length to compensate the torque produced by the main rotor. Long length makes it worth to optimize it. Generally Tail rotor drive shaft underwent variable amplitude non-proportional loading but it does not make noticeable error if we analysis constant amplitude loading at working condition load. Other hypothesis in this article can be reported as:

1. Stress concentration factor does not depend on shaft size so the optimization of simple shaft can be extended to real one.

2. There is not any micro crack in the drive shaft so using stress and strain life methods is adequate for life estimation

3. Shear stress produced by radial force in the shaft is low in comparison to bending moment produced by this force.

Several investigations has been done in this field. Prasanth and Prabhu designed an automotive manual transmission shaft for its better performance. They do Sensitivity analysis and optimization on the best among material to optimize the constraint in the aim to get minimum weight and stress and results revealed that the Ti6Al4V has the better result than other materials, which were considered [1]. Rangaswamy and Vijayarangan minimized the weight of shaft that was subjected to the constraints such as torque transmission, torsional buckling capacities, and fundamental lateral natural frequency by genetic algorithm. It was shown that The usage of composite materials and optimization techniques has resulted in considerable amount of weight saving in the range of 48 to $86 \%$ when compared to conventional steel shaft [2]. Ooi et.al optimized a hollow shaft with a rib at both ends. The torsional stress of the three-dimensional shaft modeled was determined using finite element analysis (FEA) and validated by experimental testing. The hollow shaft thickness, rib thickness, depth of spokes, rib fillet radius, and number of spokes are the five of parameters considered in the torsional strength analysis of the rib [3]. Li et.al presented a shear based evolutionary algorithm for the cross-section design of shafts subjected to torsion. In the applied method, finite element 
analysis was employed to find the shear stress distribution throughout the cross sectional area of the shaft. A number of typical examples demonstrate that proposed approach was effective in solving design problems for both simply-connected and multy-connected cross-sections involving reshaping of both interior and exterior boundaries [4]. Lindsey and Fatemi investigated the effect of periodic overloads on fatigue behavior of steels. Life predictions were performed by implementing the linear damage rule along with the constant amplitude fatigue data and curves and then compared to experimental results. It was observed Use of the LDR and SWT mean stress parameter increased the accuracy of life predictions

For some cases.[5]. Li et.al deals with simulation for cyclic stress/strain evolutions and redistributions, and evaluation of fatigue parameters suitable for estimating fatigue lives under multi-axial loadings. The local cyclic elastic-plastic stress-strain responses were analyzed using the incremental plasticity procedures of ABAQUS finite element code for both smooth and notched specimens. It was shown the equivalent strain range of ASME code approach based on the distortion energy, can provide good predictions of fatigue life by taking into account some modifications for non-proportional effects, and using the cyclic stress/strain ranges by more accurate simulations [6].

Khan and Sahai made a comparison between different modern populations based Optimization methods applied to the design of scan able circular antenna arrays. Simulation results show that differential evolution and particle swarm optimization have similar performances and both of them had better performance compared to Genetic algorithms when all algorithms are allowed equal computation time [7]. Zhijie et.al showed By analyzing and comparing two kinds of important swarm intelligent algorithm, the selecting operation in GA has the character of directivity, and the comparison experiment of two kinds of algorithm is designed in the article, and the simulation result shows that the GA has strong ability of global searching, and the convergence speed of PSO is very quick without too many parameters, and could achieve good global searching ability [8].

Panda and Padhy comprised particle swarm optimization and genetic algorithm for FACTS-based controller design. The design problem of the FACTS-based controller was formulated as an optimization problem and both PSO and GA optimization techniques were employed to search for optimal controller parameters. The performance of both optimization techniques in terms of computational effort, computational time, and convergence rate was compared. It was shown the computational time for GA was low compared to the PSO optimization algorithm. The higher computational time for PSO was due to the communication between the particles after each generation [9].

\section{Masterial Selection}

Different materials are being used in manual transmission shaft from an earlier time. In Aerospace field, using high strength Aluminum alloy is so frequent due to reduction weight importance. One of the most popular kinds of these alloys that are mostly used in aerospace industry is AL 7075-T6 alloy. Adding chromium cause the AL 7075-T6 alloy has a high strength and good corrosion cracking resistance. Heat treatment has a major effect in this alloy. Chemical composition, mechanical properties and fatigue properties of AL 7075-T6 alloy is shown in table 1, 2 and 3 respectively.

Table 1. Chemical composition of AL 7075-T6 alloy [10].

\begin{tabular}{|c|c|c|c|c|c|c|c|c|c|c|}
\hline Alloy & $\mathbf{A L}$ & $\mathbf{S i}$ & $\mathrm{Fe}$ & $\mathbf{C u}$ & Mn & Mg & $\mathrm{Cr}$ & $\mathbf{Z n}$ & $\mathbf{T i}$ & other \\
\hline AL7075-T6 & Base & 0.4 & 0.5 & 1.5 & 0.3 & 2.5 & 0.18 & 5.5 & 0.1 & 0.5 \\
\hline
\end{tabular}

Table 2. Mechanical properties of AL 7075-T6 alloy [10].

\begin{tabular}{|c|c|c|c|c|c|}
\hline Alloy & Ultimate tensile strength & Tensile Yield strength & Elongation at break & Modulus of elasticity & Poison ratio \\
\hline AL7075-T6 & $572(\mathrm{MPa})$ & $503(\mathrm{MPa})$ & $11 \%$ & $71.7(\mathrm{GPa})$ & 0.33 \\
\hline
\end{tabular}

Table 3. Cyclic and fatigue properties of AL 7075-T6 alloy [10].

\begin{tabular}{llllll}
\hline Alloy & b & c & $\boldsymbol{\sigma}_{f}^{\prime}(\mathbf{M P a})$ & $\boldsymbol{S}_{\boldsymbol{f}}(\mathbf{M P a})$ & $\boldsymbol{\varepsilon}_{f}^{\prime}$ \\
\hline AL7075-T6 & -0.095 & -0.987 & 776 & 2.57 & 108.1 \\
\hline
\end{tabular}

\section{Applied Models}

In this section, seven life estimation models that three of them are based on strain-life prediction and others based on stress-life prediction are discussed.

\subsection{Stress-Life Estimation Models}

Stress-life models were the first type of life estimation. In these methods, S-N curve of the material is used to estimate the life of the specimen. Equation 1 to 3 represents Modified
Goodman, Gerber and Morrow equations [11].

$$
\begin{aligned}
& \frac{S_{a}}{S_{f}}+\frac{S_{m}}{S_{u}}=\frac{1}{n} \\
& \frac{S_{a}}{S_{f}}+\left(\frac{S_{m}}{S_{u}}\right)^{2}=\frac{1}{n} \\
& \frac{S_{a}}{S_{f}}+\frac{S_{m}}{\sigma_{f}}=\frac{1}{n}
\end{aligned}
$$

Where $S_{\mathrm{a}}$ is alternative stress, $S_{m}$ is mean stress, $S_{u}$ is ultimate strength, $S_{f}$ is fatigue limit, $n$ is factor of safety and $\sigma_{f}$ 
is true fracture strength.

\subsection{Strain-Life Estimation Models}

The strain-life approach involves the techniques for converting the loading history, geometry, and materials properties input into a fatigue life prediction. The Coffin-Manson total strain-life method was proposed as equation $4[11]$.

$$
\frac{\Delta \varepsilon}{2}=\frac{\sigma_{f}^{\prime}}{E}\left(2 N_{f}\right)^{b}+\varepsilon_{f}^{\prime}\left(2 N_{f}\right)^{c}
$$

Where $N_{f}$ is the fatigue life, $\sigma_{f}^{\prime}$ is the fatigue strength coefficient, $E$ is the modulus of elasticity, $b$ is the fatigue strength exponent, $\varepsilon_{f}^{\prime}$ is the fatigue ductility coefficient, and $c$ is the fatigue ductility exponent.

In conjunction with the local strain-life approach, many models have proposed to quantify the effect of mean stresses on fatigue behavior. The commonly used models in the ground Aerospace industry are those by Morrow [6] and by Smith, Watson, and Topper [11]. These two models are described in the following sections. Morrow has proposed the following relationship when a mean stress is expressed in Eq (5)[11].

$$
\varepsilon_{a}=\frac{\sigma_{f}^{\prime}-\sigma_{m}}{E}\left(2 N_{f}\right)^{b}+\varepsilon_{f}^{\prime}\left(2 N_{f}\right)^{c}
$$

Smith, Watson, and Topper [6] proposed another mean stress model, which is called Smith-Watson-Topper (SWT), mean stress correction. It is mathematically defined in Eq (11).

$$
\sigma_{\max } \varepsilon_{a} E=\left(\sigma_{f}^{\prime}\right)^{2}\left(2 N_{f}\right)^{2 b}+\sigma_{f}^{\prime} \varepsilon_{f}^{\prime} E\left(2 N_{f}\right)^{b+c}
$$

Where $\max \sigma_{\max }$ is the maximum stress, and $\varepsilon_{a}$ is the strain amplitude.

\subsection{Journal Bearing Relations[12]}

In this article besides the shaft optimization, we utilize 2 modern population basedOptimization methods (PSO and GA) to optimize Journal bearings. In journal bearing, most of variables can be determine by Somerfield number, which is function of Temperature. We can distinguish two groups of variables in the design of sliding bearings. In the first group, those whose values either are given or are under the control of the designer such as viscosity, rotary speed, pressure, and bearing dimension and those whose values are depend of the first group such as friction coefficient, the temperature rise, minimum film thickness, and volume flow rate. We utilize SAE type lubricant. It's relation with temperature is disclosed in Equation 7 and the constants of this equation is shown in table 4.

$$
\mu=\mu_{0} e^{\left[\frac{b}{1.8 \times T+127}\right]}
$$

Minimum film thickness value, lubrication flow, flow ratio, and maximum pressure have exponential relation with Somerfield number. the Equation 8 shows their relation and Table 5-8 disclose the constants of this equations.

$$
\text { variable }=a S^{b}+c
$$

Table 4. Values of the constants of equation 7

\begin{tabular}{lll}
\hline SAE number & $\boldsymbol{\mu}_{\mathbf{0}}(\boldsymbol{m p a} . \boldsymbol{s})$ & $\boldsymbol{b}$ \\
\hline 10 & 0.0158 & 1158.5 \\
20 & 0.0136 & 1271.6 \\
30 & 0.0141 & 1360.0 \\
40 & 0.0121 & 1474.4 \\
50 & 0.017 & 1509.6 \\
60 & 0.0187 & 1564.0 \\
\hline
\end{tabular}

Table 5. Constant of equation 8 for Minimum film thickness values.

\begin{tabular}{llll}
\hline L/D & a & b & c \\
\hline 0.25 & 0.4769 & 0.3142 & -0.09841 \\
0.5 & 1.2870 & 0.1277 & -0.09841 \\
1 & -3.3570 & -0.0411 & 4.11500 \\
6 & -0.2756 & -0.2880 & 1.2060 \\
\hline
\end{tabular}

Table 6. Constantof equation 8 for lubrication flow values.

\begin{tabular}{llll}
\hline $\mathbf{L} / \mathbf{D}$ & $\mathbf{a}$ & $\mathbf{b}$ & $\mathbf{c}$ \\
\hline 0.25 & 54.15 & 0.2188 & -9.07 \\
0.5 & 114.40 & 0.1022 & -53.87 \\
1 & -117.10 & -0.0778 & 188.9 \\
6 & -4.535 & -0.4657 & 73.01 \\
\hline
\end{tabular}

Table 7. Constant of equation 8 for flow ratio values.

\begin{tabular}{llll}
\hline $\mathbf{L} / \mathbf{D}$ & $\mathbf{a}$ & $\mathbf{b}$ & $\mathbf{c}$ \\
\hline 0.25 & -1.818 & 0.2677 & 6.781 \\
0.5 & -4.055 & 0.1147 & 8.276 \\
1 & -92.16 & 0.0028 & 95.77 \\
6 & -0.5823 & -0.351 & 3.592 \\
\hline
\end{tabular}

Table 8. Constant of equation 8 for flow ratio values.

\begin{tabular}{llll}
\hline $\mathbf{S}$ & $\mathbf{a}$ & $\mathbf{b}$ & $\mathbf{c}$ \\
\hline 0.25 & -0.309 & 0.4169 & 1.048 \\
0.5 & -0.7139 & 0.2427 & 1.241 \\
1 & -8.612 & 0.017 & 8.906 \\
\hline
\end{tabular}

We employ coding in MATLAB software to optimize maximum pressure in journal bearing. There are two constrains in optimization. The first one applied to minimum film thickness. The second one defined for maximum temperature. These constrain displayed in equation 9 and 10 respectively.

$$
\begin{gathered}
h_{0} \geq 0.00004 d+0.005 \\
T_{\max }<107\left({ }^{\circ} \mathrm{C}\right)
\end{gathered}
$$

\section{Results and Discussion}

\subsection{Shaft Optimization}

Besides shaft radius, bearing location, number of bearings and length of bearing are other design variables. Geometry of shaft has been assumed simply cylindrical. In order to apply out of phase condition for life estimation we should make two separate fatigue analysis and connect them. Therefore, we are 
able to apply the non-proportional loading and get the results in combination solution. Fig 1 displays the shaft geometry

with fore bearing and its loading in two different fatigue analyses.

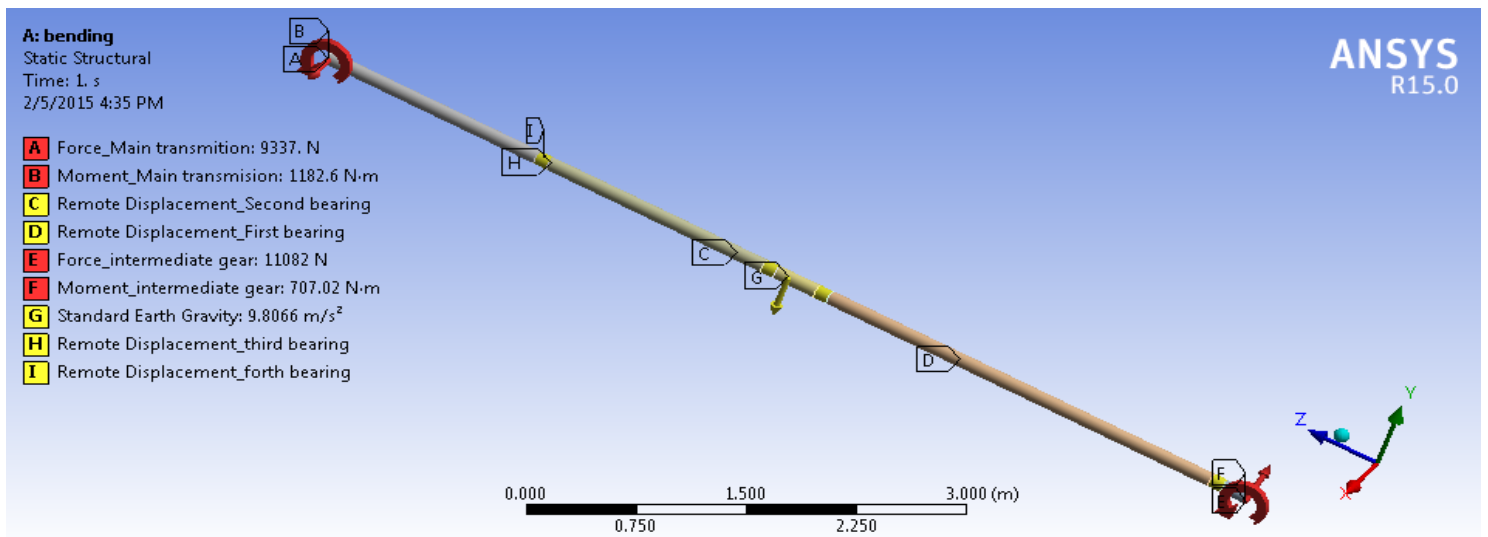

(a)

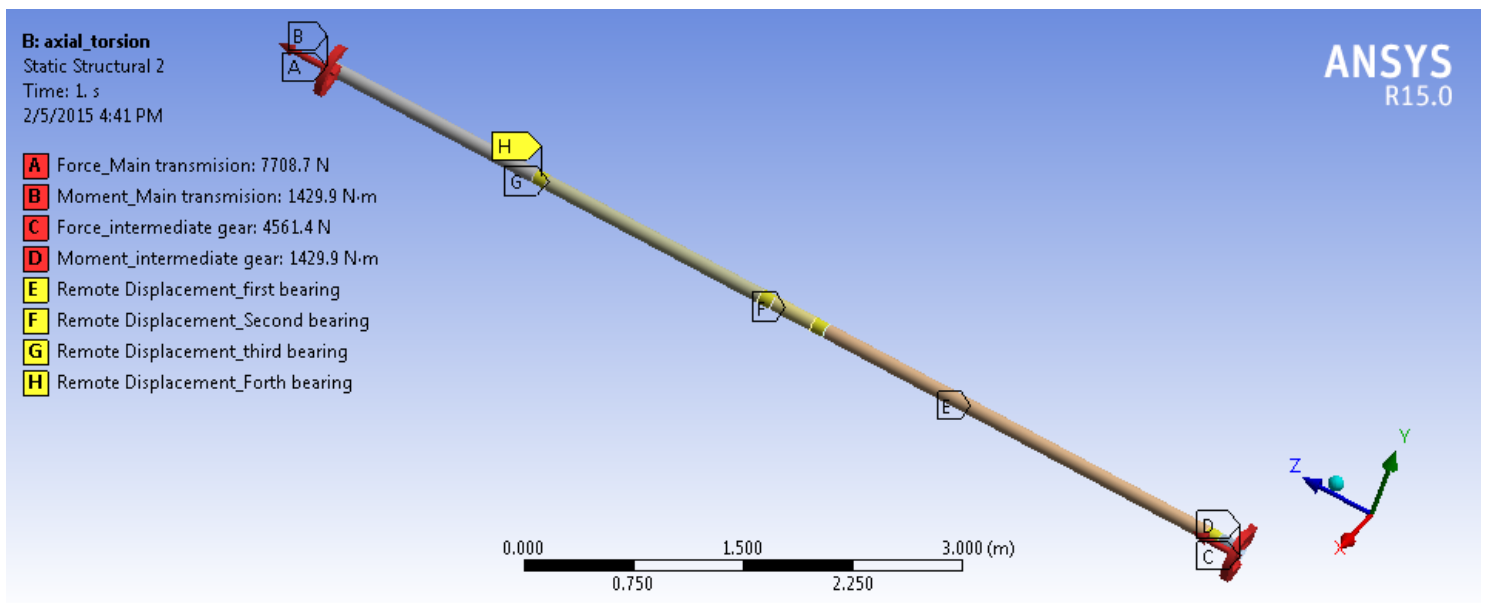

(b)

Fig. 1. The shaft geometry and its loading (a) bending (b) axial and rotation.

Objective functions in shaft optimization considered as mass of the shaft and the safety factor. The effect of design variables except number of bearing which needs a new analysis execution has been shown in fig 2 . Fig 3 shows the effects of two different selected design variables on the safety factor. Possible results for mass and safety factor are shown in fig 4

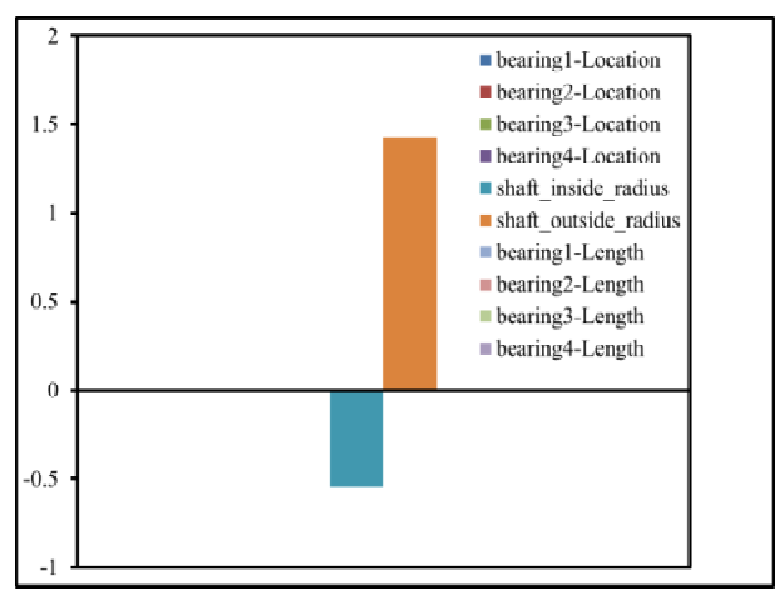

(a)

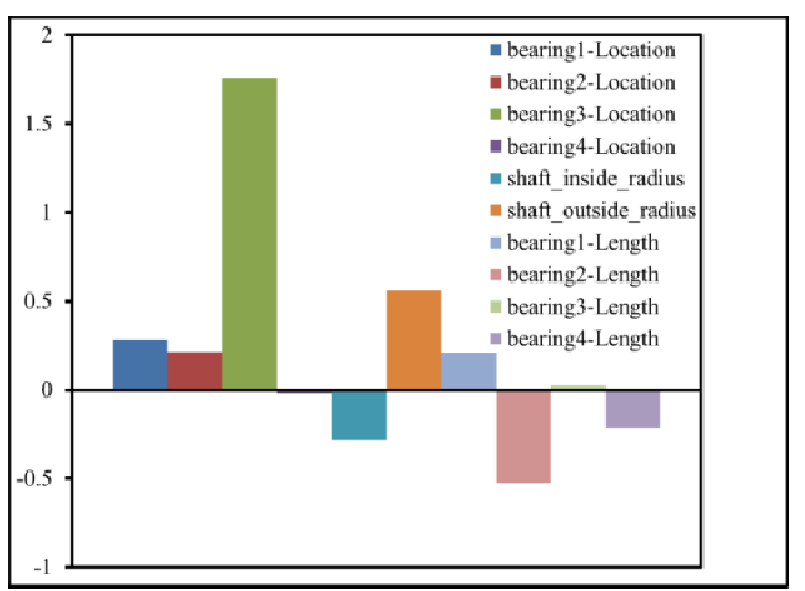

(b)

Fig. 2. Design variables effects on objective functions (a) mass (b) safety factor. 


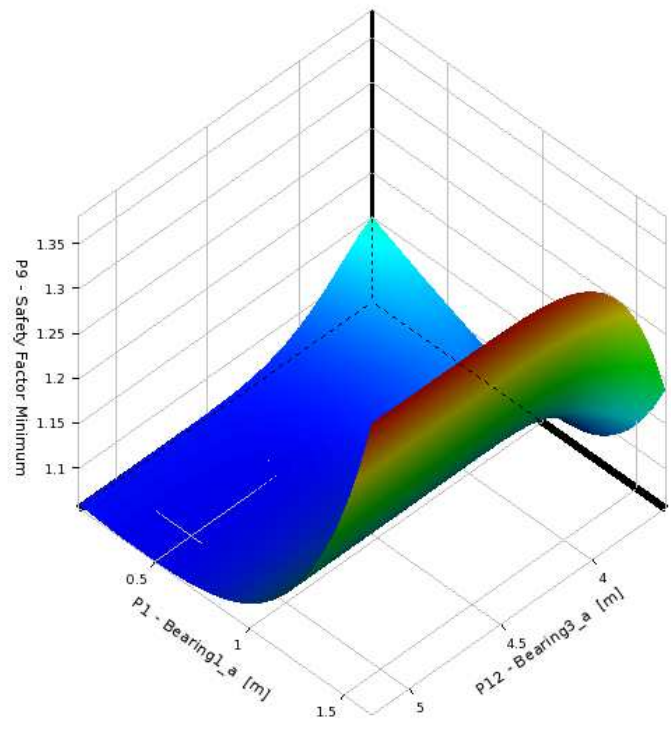

(a)

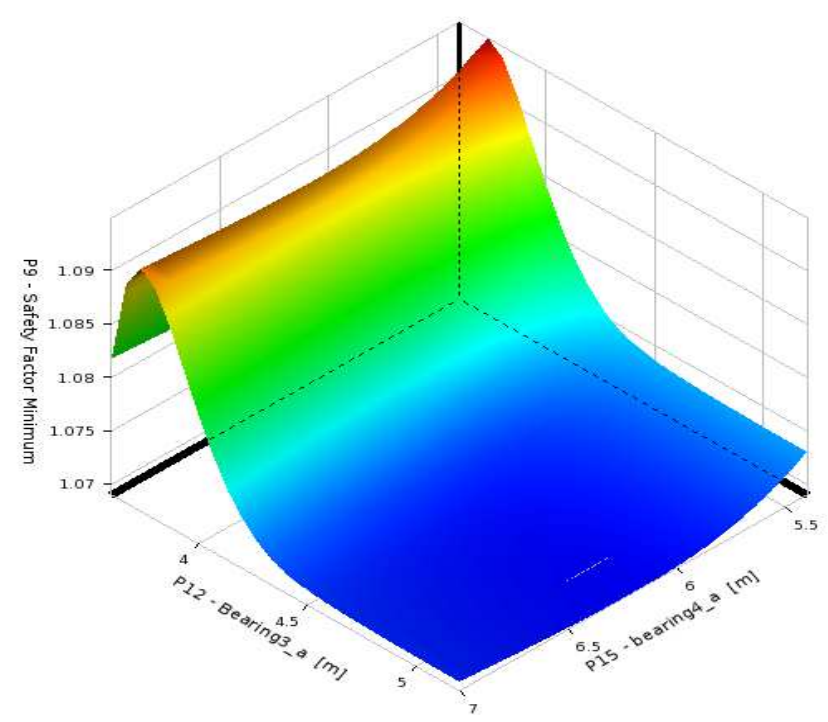

(b)

Fig. 3. Design variables effects on objective functions (a) mass (b) safety factor.

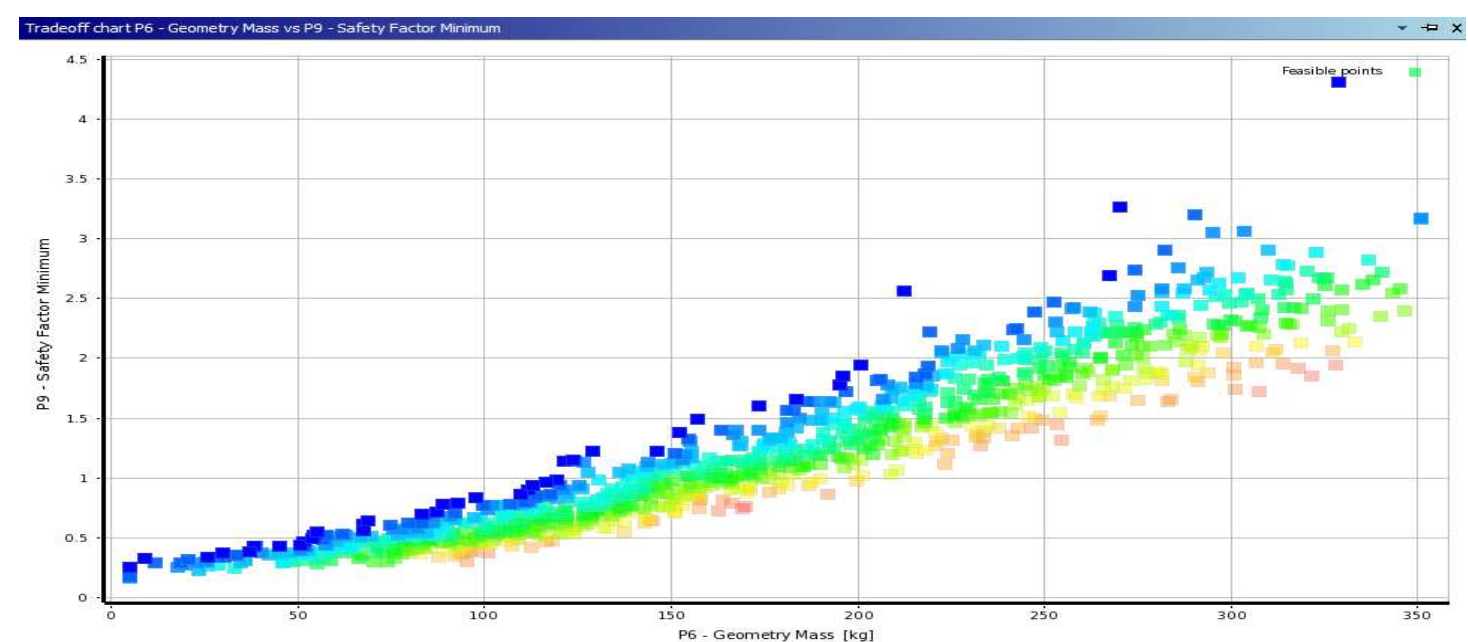

Fig. 4. Possible results for mass and safety factor.

If we repeated this process for 5 bearing and six bearing condition. Best value of design points were provided as reported in Table 9. Mass of the shaft in different cases are shown in table 10. Safety factor provided by different methods are represented in fig 5 . It is observed choosing five bearing is better than other circumstances.

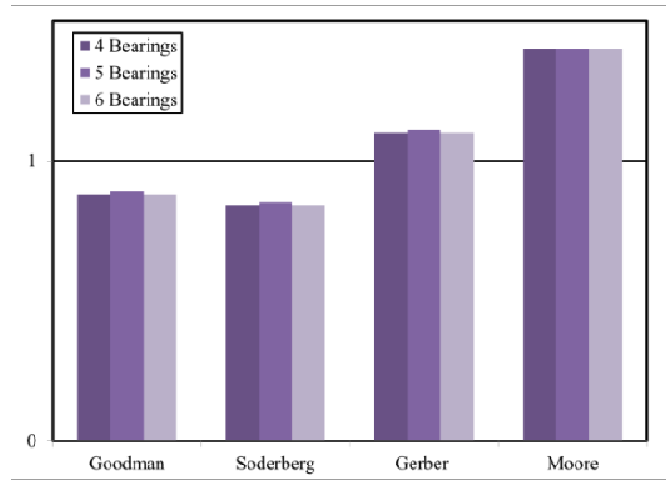

(a)

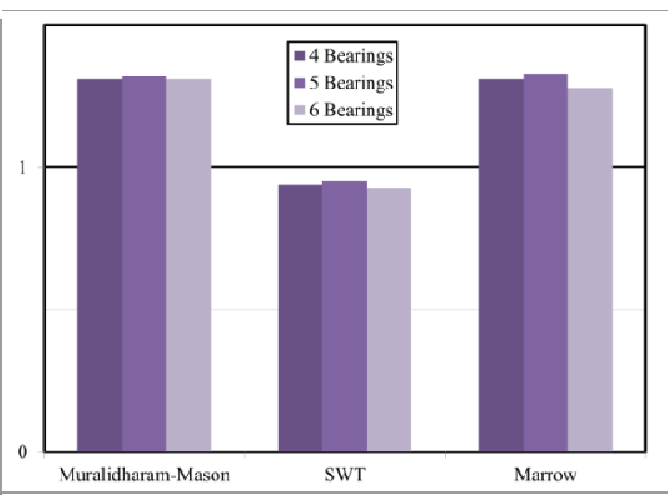

(b)

Fig. 5. Safety factor provided by (a) stress life methods (b) strain life methods. 
Table 9. Best value of design points.

\begin{tabular}{llll}
\hline & 4 bearing & 5 bearing & 6 bearing \\
\hline Bearing Location1 $(\mathrm{m})$ & 0.19 & 1.54 & 1.11 \\
Bearing Length1 $(\mathrm{m})$ & 0.08 & 0.15 & 0.11 \\
Bearing Location2(m) & 3.3 & 2.36 & 2.3 \\
Bearing Length2(m) & 0.12 & 0.22 & 0.14 \\
Bearing Location3(m) & 3.7 & 3.8 & 2.7 \\
Bearing Length3(m) & 0.21 & 0.09 & 0.11 \\
Bearing Location4(m) & 5.5 & 4.22 & 4.1 \\
Bearing Length4(m) & 0.13 & 0.12 & 0.15 \\
Bearing Location5(m) & - & 6.12 & 5.77 \\
Bearing Length5(m) & - & 0.14 & 0.15 \\
Bearing Location6(m) & - & - & 6.7 \\
Bearing Length6(m) & - & - & 0.12 \\
Inside radius $(\mathrm{m})$ & 0.035 & 0.039 & 0.036 \\
Outside radius $(\mathrm{m})$ & 0.053 & 0.054 & 0.054 \\
\hline
\end{tabular}

Table 10. Mass of the shaft in different implemented cases.

\begin{tabular}{llll}
\hline & 4 bearing & 5 bearing & 6 bearing \\
\hline Mass $(\mathrm{Kg})$ & 97.8 & 88.95 & 101 \\
\hline
\end{tabular}

\subsection{Bearing Optimization}

Bearing design is a touch and go process, in other words we should estimate the temperature rise then design the bearing and calculate the real temperature rise and compare the real temperature rise and the estimated temperature rise and make a better estimation in the next step. This process will go on until the error become suitably small.

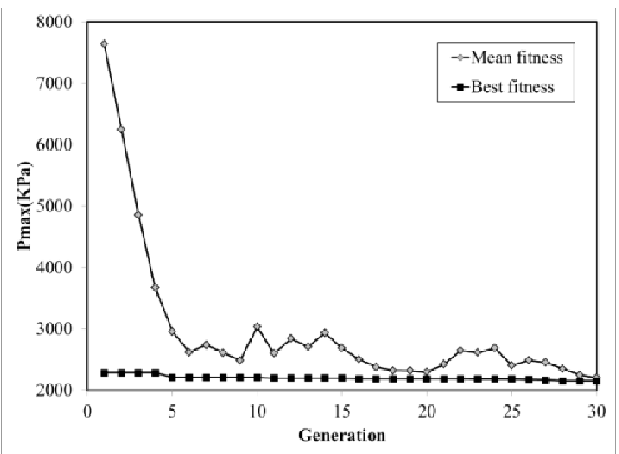

(a)
We implemented two population based (PSO and GA) optimization methods to optimize the bearing maximum pressure.

In the past section, it is observed that case "five bearings" is better than four and six bearings. In this section, we make an appraisal between two methods. Change of best individual and mean individual of the population for the first bearing until fifth bearing has been shown in fig 6-10.

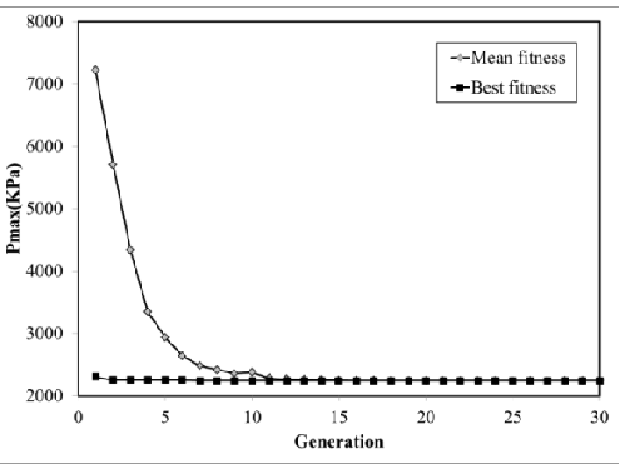

(b)

Fig. 6. Mean and best fitness variation for first bearing (a) GA algorithm (b) PSO algorithm.

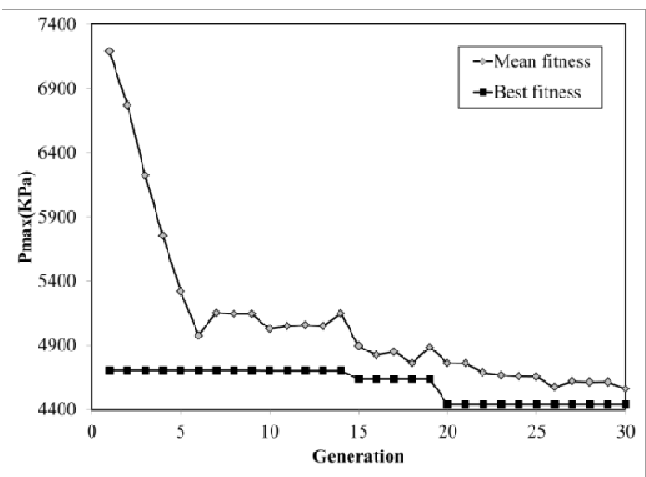

(a)

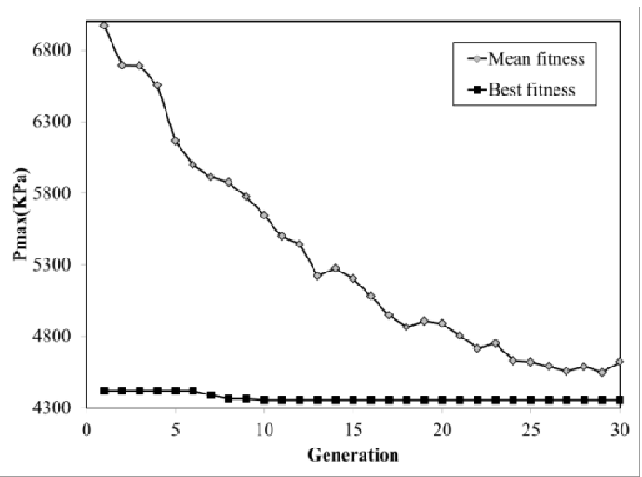

(b)

Fig. 7. Mean and best fitness variation for Second bearing (a) GA algorithm (b) PSO algorithm. 


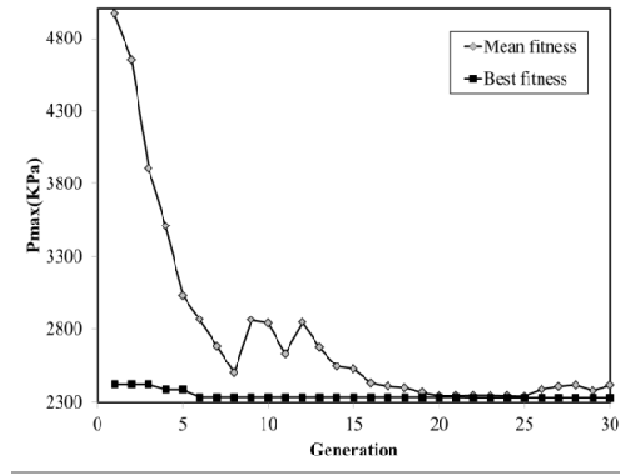

(a)

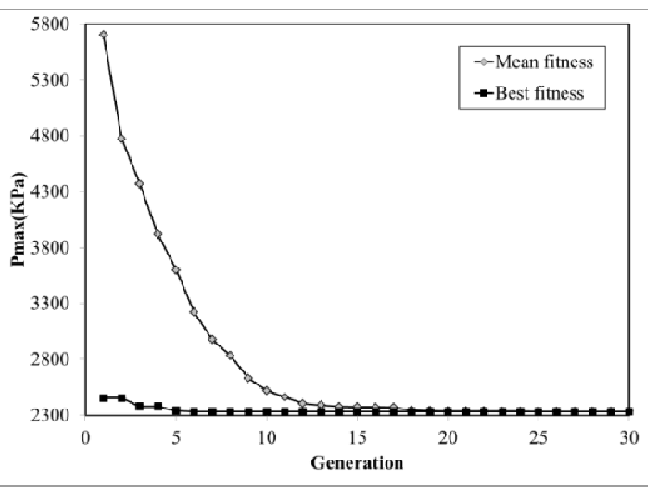

(b)

Fig. 8. Mean and best fitness variation for third bearing (a) GA algorithm (b) PSO algorithm.

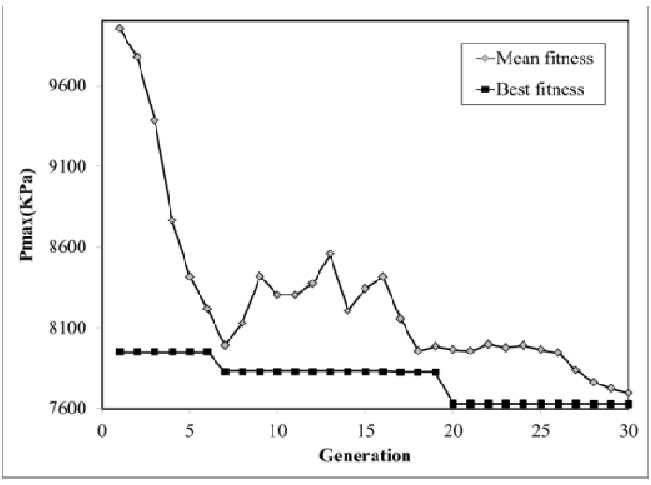

(a)

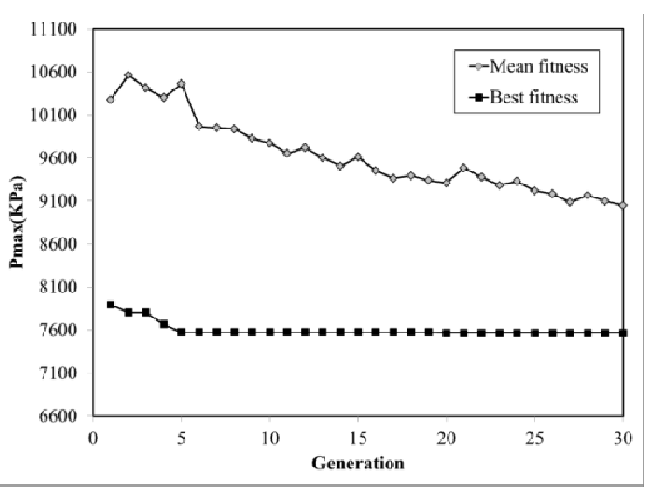

(b)

Fig. 9. Mean and best fitness variation for forth bearing (a) GA algorithm (b) PSO algorithm.

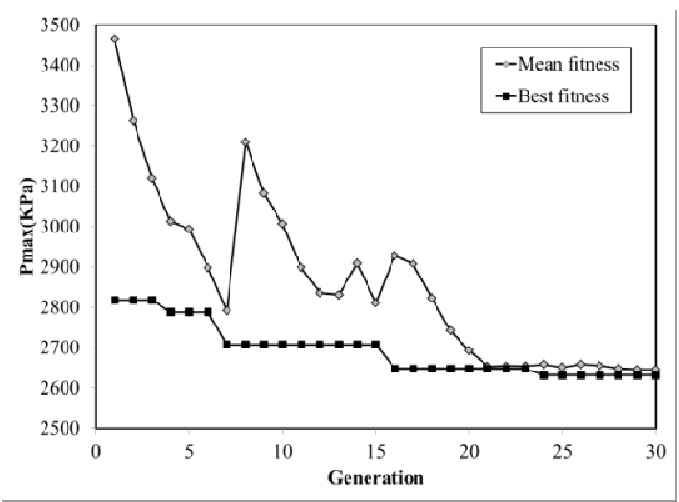

(a)

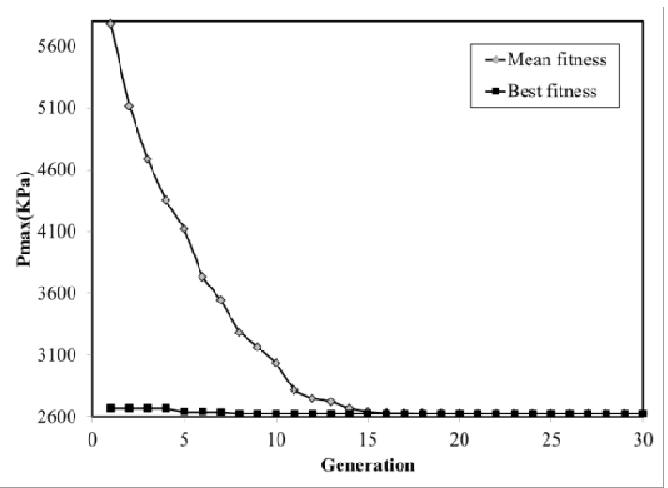

(b)

Fig. 10. Mean and best fitness variation for fifth bearing (a) GA algorithm (b) PSO algorithm.

\section{Conclusion}

This investigation was performed to analysis the influence of the bearing location and length on the shaft mass. It is observed that four bearing cause a better conclusion in the drive shaft optimization. Subsequently we optimized the maximum bearing pressure by two non-mathematical based optimization methods named GA and PSO. It is observed that PSO algorithm can find the optimized solution in lower time than GA algorithm but the probability of attaining local points in this method is higher than GA algorithm.

\section{References}

[1] Prasanth, K., Prabhu, S. (2014). Design optimization and analysis of an automotive manual transmission shaft using Titanium alloy (TI6AL4V), International Journal of Mechanical And Production Engineering, vol. 4, no. 2, p. 320-334.

[2] Rangaswamy, T.Vijayarangan, S. (2005).Optimal Sizing and Stacking Sequence of Composite Drive Shafts, Materials Science. Materials Science, vol. 11, no. 2, p. 1392-1320. 
[3] Ooi, J.B. Wang, X. Lim, Y.P.Tan, K.Ch. (2013). 3Parametric Optimization of the Output Shaft of a Portal Axle using Finite Element Analysis. Materials Science, vol. 59, no. 10, p. 613-619.

[4] Li, Q. Steven, G.P.Querin, O.M.Xie, Y.M. (2001). Stress based optimization of torsional shafts using an evolutionary procedure. International Journal of Solid and Structure, vol. 38 , p. 5661-5677.

[5] Fatemi, A.Plaseied, A.Khosrovaneh, A.K. (2005). Application of bi-linear $\log -\log \mathrm{S}-\mathrm{N}$ model to strain-controlled fatigue data of aluminum alloys and its effect on life predictions. International Journal of Fatigue, vol. 27, p.1040-1050.

[6] Rahman, M.M.Kadirgama, K.Noor, M.M.Rejab, R.M. (2009). Fatigue Life Prediction of Lower Suspension Arm Using Strain-Life Approach. European Journal of Scientific Research, vol. 30, no. 3, p. 437-450.

[7] Pandura, M.A., Brizuela, C.A., Balderas, D.A. (2009). A comparison of genetic algorithms, particle swarm optimization and the diferential evolution method for the design of scannable circular antenna arrays, Progress In Electromagnetics Research, vol. 13, p. 171-186.

[8] Zhijie, L., Xiaodong, L., Xiaodong, D. (2010Comperative research on particle swarm optimization and genetic algorithm, Computer and Information Science, vol. 3, no. 1, p. 120-127.

[9] Panda, S., Padhy, N.P. (2008). Comparison of particle swarm optimization and genetic algorithm for FACTS-based controller gesign, Applied Soft Computing, vol. $8, p$. 1418-1427.

[10] Lindsey, J., Fatemi, A. (2008). Applicability of constant amplitude fatigue data to life predictions under variable amplitude service loading, Recent Advances in Mechanical Engineering Applications, ISBN: 978-960-474-345-2.

[11] Li, B., Reis, L.Freitas, M. (2006). Simulation of cyclic stress/strain evolutions for multiaxial fatigue life predicti, International Journal of Fatigue, vol. 28, p. 451-458.

[12] J. Shigley, E. Gordon, R. Mischke, Mechanical engineering design, McGraw-hill, 2004. 